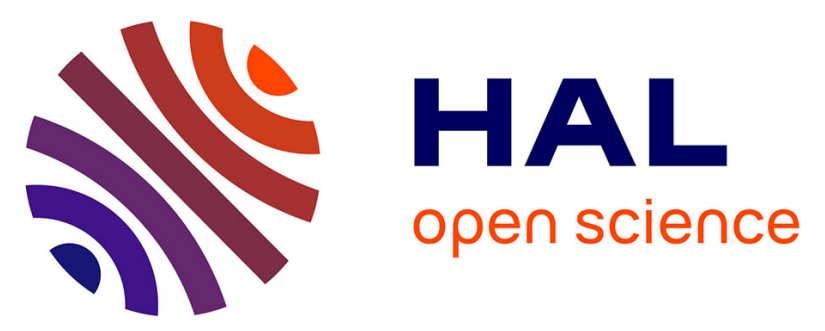

\title{
Enzymatic hydrolysis at high dry matter content: The influence of the substrates' physical properties and of loading strategies on mixing and energetic consumption
}

Federico Battista, Mélanie Gomez Almendros, Romain Rousset, Serge Boivineau, Pierre-Antoine Bouillon

\section{To cite this version:}

Federico Battista, Mélanie Gomez Almendros, Romain Rousset, Serge Boivineau, Pierre-Antoine Bouillon. Enzymatic hydrolysis at high dry matter content: The influence of the substrates' physical properties and of loading strategies on mixing and energetic consumption. Bioresource Technology, 2018, 250, pp.191 - 196. 10.1016/j.biortech.2017.11.049 . hal-01931421

\section{HAL Id: hal-01931421 \\ https://hal-ifp.archives-ouvertes.fr/hal-01931421}

Submitted on 22 Nov 2018

HAL is a multi-disciplinary open access archive for the deposit and dissemination of scientific research documents, whether they are published or not. The documents may come from teaching and research institutions in France or abroad, or from public or private research centers.
L'archive ouverte pluridisciplinaire HAL, est destinée au dépôt et à la diffusion de documents scientifiques de niveau recherche, publiés ou non, émanant des établissements d'enseignement et de recherche français ou étrangers, des laboratoires publics ou privés. 
ENZYMATIC HYDROLYSIS AT HIGH DRY MATTER CONTENT: THE INFLUENCE OF THE SUBSTRATES' PHYSICAL PROPERTIES AND OF LOADING STRATEGIES ON MIXING AND ENERGETIC CONSUMPTION

Federico Battista*, Mélanie Gomez Almendros, Romain Rousset,

Serge Boivineau, Pierre-Antoine Bouillon

6

IFP Energies Nouvelles, Rond-point de l'échangeur de Solaize BP 3, 69360 Solaize,

7 France

*Corresponding Author: Phone: +33437702143; email: federico.battista@ifpen.fr

\section{ABSTRACT}

The present work investigates the impact of the physical properties and loading strategies of wheat straw and miscanthus on enzymatic hydrolysis at high DM concentration. Three parameters have been chosen to evaluate the enzymatic hydrolysis performance: (i) the mixing time, (ii) the energetic mixing consumption and (iii) the glucose concentration. It was demonstrated that the hydrolysis of miscanthus is easy to perform and has low viscosity. On the contrary, the higher porosity grade of wheat straw than miscanthus ( $73 \%$ against $52 \%)$ contributed to have a very high viscosity at $20 \% \mathrm{w} / \mathrm{w}$ DM. The development of a fed-batch strategy allowed the reduction of viscosity inducing the energetic consumption lowering from $30 \mathrm{~kJ}$ to $10 \mathrm{~kJ}$. It has been also proven that the miscanthus addition in wheat straw achieved to decrease mixing energy consumption at $5-8 \mathrm{~kJ}$, when it represented more than $30 \%$ of the total mass of the reaction medium. 
22 KEYWORDS: Bioethanol; High Dry Matter; Mixing; Enzymatic hydrolysis; Energy

23 consumption; Lignocellulosic materials

\section{INTRODUCTION}

The global warming, due to the increase of the greenhouse gas (GHG) emissions and the simultaneous depletion of fossil fuels, have encouraged the research of alternative and clean energy sources for the anthropic activities. In particular, the bioethanol industry boomed in the last decades (Battista et al., 2016a). Bioethanol production usually starts from simple sugars derived from cane and corn (first generation biofuels), whose fermentation has very good efficiency. Nevertheless, this production is expensive and non-sustainable because of the competitive use of these substrates with food industry (Clomburg and Gonzalez, 2013). Agro-food residues (second generation biofuels) are becoming important substrates for bioethanol production, limiting the use of fields for non-food production. Wheat straw and miscanthus are common second generation substrates for the bioethanol production. Wheat straw is a waste material from agricultural production and miscanthus is a grass family crop with a high energetic yield by its beneficial chemical composition (low content of lignin) (Lewandowska et al., 2016).

Bioethanol production involves four steps: (i) the pretreatments of the substrates, (ii) the hydrolysis to convert ligno-cellulosic material into glucose, (iii) the fermentation of glucose in ethanol and (iv) the distillation. The pretreatments of straw and miscanthus are necessary to optimize the glucose concentration during the hydrolysis and to reduce the viscosity of the reaction medium (Battista et al., 2016b). The pretreatment stage is followed by the hydrolysis, often conducted by purified enzymes able to degrade hemicellulose and cellulose into soluble sugars (Zhou et al., 2008). The enzymatic 
hydrolysis has currently high yields (75-85\%) and improvements are still projected

$47 \quad(85-95 \%)$ (Balat, 2011).

The last phase of the bioethanol production is represented by the distillation. It has been evaluated that to be economically advantageous the distillation requires a minimum ethanol concentration of $4 \% \mathrm{w} / \mathrm{w}$, which means a minimum glucose concentration of $8 \%$ $w / w$ and an associate ligno-cellulose loading of at least $15 \% w / w$ DM content during the enzymatic hydrolysis (McIntosh et al., 2016). Working at high DM concentration also permits to reduce the volume of the reactor and consequentially to have lower economic and energetic costs of the process (Larsen et al., 2008).

Typical enzymatic hydrolysis of lignocellulosic materials is conducted at low DM concentration (maximum 5\% w/w) to ensure a good contact between enzymes and substrates (Boussaid and Saddler, 1999), (Xue et al., 2012). There are few studies regarding the enzymatic hydrolysis at high DM concentration. Kristensen et al. (2009) and Jorgensen et al. (2007) have demonstrated that the conversions of cellulose into glucose decreases by the increasing of DM concentration. In addition, Cara et al. (2007) and Battista et al. (2016c) have underlined that at high DM content, the complexity of the lignocellulosic polymers, causes an increase of the reaction medium viscosity and consequentially bad mixing within the bioreactor. The mechanism by which cellulases permit the hydrolysis of cellulose follows three steps: (i) external mass transfer of enzyme, (ii) diffusion/adsorption of the enzyme on the substrate surface and (iii) cellulase catalytic action. The overall reaction rate is determined by the rates of these three events occurring in sequence. If the external mass transfer is neglected (at low DM content), the overall reaction rate will be controlled by the second step (internal diffusion). At high DM content, the mixing is not efficient: the external mass transfer 
controls the overall reaction rate (Corre et al., 2016) and the hydrolysis efficiency is $20 \%$ lower than observing at 5\% w/w DM concentration (Xue et al., 2012).

The aim of this work is the improvement of the enzymatic hydrolysis of wheat straw and miscanthus at high DM concentration $(20 \% \mathrm{w} / \mathrm{w})$, reducing the reaction medium viscosity. The physical properties influence on viscosity has been observed and different loading strategies of batch and fed-batch have been tested on straw, on miscanthus and on a combination of both substrates. The performances of the tests have been evaluated taking into account the most important factors affecting the bioprocesses: (i) mixing time, (ii) mixing energetic consumption and (iii) the glucose concentration contained in the reaction medium at the beginning and at the end of the hydrolysis phase.

\section{MATERIALS AND METHODS}

\subsection{Substrates, enzymatic cocktail characteristic and description of the tests}

The substrates used for the tests were wheat straw and miscanthus, pretreated at appropriate operative conditions (data not shown). Table 1 summarises the physical and chemical features of the pretreated wheat straw and the pretreated miscanthus. The features of raw substrates were not available. Zhang et al. (2012) founded that soil and climate conditions influence the raw substrates porosity, which can vary in a very range: $45-85 \%$. This demonstrates that the results obtained by this work are not dependent on the substrates conditions (raw or pretreated). The content of lignin, hemicellulose and cellulose of both substrates have been determined by an external company which supplied the substrates (Table 1).

$<$ Table 1 $>$ 
93 Cellic CTec-2 (Novozymes) cellulase blend was used for all enzymatic hydrolysis tests and loadings were quoted as FPU (Filter Paper Units)/g glucan. The amount of the enzymatic cocktail has been determined following the methods by McIntosh et al, 2016. Batch and fed-batch tests have been realised using wheat straw, miscanthus and wheat straw-miscanthus mixture as substrates in order to see the rheological behavior and the conversion of the substrates into glucose. All tests, described in Table 2, have been prepared in order to reach the DM concentration of $20 \% \mathrm{w} / \mathrm{w}$ and have conducted in triplicate to ensure their repeatability. The duration of each test has been established at 5 hours, when was proved that a stable torque trend was reached. This time was not sufficient to guarantee a complete cellulose conversion in glucose. But this aspect was not relevant in this work which had the aim to investigate the correlation between the substrates feature and the apparent viscosity within the reactor.

$<$ Table 2>

S-B test has been prepared loading the reactor with $2.4 \mathrm{~kg}$ of wheat straw-water mixture ( $0.9 \mathrm{~kg}$ of wheat straw), while M-B test loading $2.4 \mathrm{~kg}$ miscanthus-water mixture $(1 \mathrm{~kg}$ of miscanthus). Fed batch tests (S-FB65, S-FB50, S-FB35, M-FB65, M-FB50 and MFB35, Table 2) consisted a first loading of the $65 \%$, the $50 \%$ and $35 \%$ of the $2.4 \mathrm{~kg}$ reaction medium at the beginning of the tests. The rest of the loading has been gradually added in equal parts after 10,30, 60, 105 and 120 minutes after the beginning of each test. These fed batch tests had the aim to improve the rheological performance into the reactor and to reduce the power consumption without decreasing the yield from cellulose to glucose. Batch tests have been also conducted on wheat straw-miscanthuswater mixtures (SM-80:20, SM-70:30, SM-50:50, SM-30:70) according the ratios reported in Table 2. 
117 The enzymatic hydrolysis of all the tests have been conducted at optimal operative conditions that are at $50^{\circ} \mathrm{C}, 50 \mathrm{rpm}$ and a $\mathrm{pH}$ range of $5.0-5.5$.

\subsection{The equipment}

The bioethanol production from wheat straw and miscanthus have been conducted in a $3 \mathrm{~L}$ reactor (Figure 1) equipped with a torque meter Kistler 4503A measuring torque till a value of $2 \mathrm{Nm}$ and with a data detection frequency variable from 1 to $10 \mathrm{~Hz}$. Data were recollected by LEIRI software reporting them in an Excel file. The reactor was also equipped with a water-heater and with temperature and $\mathrm{pH}$ control sensors. The mixing system was an helicoidal impeller properly designed to deal with high DM concentration and high viscosity medium. The helicoidal impeller (Figure 1) had a diameter of $130 \mathrm{~mm}$ and is located at $30 \mathrm{~mm}$ from the bottom of the reactor.

\subsection{Analytical methods}

DM of the wheat straw and miscanthus have been determined according to standard methods described in literature (APHA/AWWA/WEB, 1998). DM represented the content of solids present in the substrates, including the inert materials and the degradable ones (Battista et al., 2016b). The apparent density was determined by the use of Archimedes' principle (Zhao et al., 2016).

The apparent viscosity of the wheat straw-water and of miscanthus-water mixtures have been determined at 10 and $20 \% \mathrm{DM} w / w$ before the beginning of the enzymatic hydrolysis. The equipment used was the viscometer DV-II-PRO by Brookfield provided with a cross rotating spindle working at $50 \mathrm{rpm}$.

The glucose concentration has been quantified by an enzymatic reaction using the GLUCOSTAT YSI2700 at the beginning and at the end of the tests. 
Porosity of the substrates was a very important parameter that was directly linked to the absorption capacity of water: obviously, a major grade of porosity favored the absorption of water molecules by substrates. By this way, the amount of water available for the dispersion of the substrates particles decrease, affecting the viscosity of the reaction medium. The grade of porosity and the average volume pore for macroporosity, mesoporosity and microporosity have been evaluated by $\mathrm{N}_{2}$ adsorption isotherms method. Initially the sample was degassed at $60{ }^{\circ} \mathrm{C}$ for $48 \mathrm{~h}$. The average pore volume was obtained using the Horvath-Kawazoe approximation (Horvath and Kawazoe, 1983). The absorption capacity of wheat straw and miscanthus has been evaluated in qualitative way by a simple experiment: $50 \mathrm{~g}$ of dry straw and $50 \mathrm{~g}$ dry of miscanthus have been located in two different separatory funnels. $100 \mathrm{~mL}$ of distilled water have been poured into the funnels at $t=0$. The time of the beginning of water percolation from the outlet of the separatory funnels has been measured in order to have qualitative evaluation of the different grade of porosity of both substrates. Also, at the end of order to have an estimation of the adsorption capacity of straw and miscanthus. The average equivalent diameter of the particles of both substrates has been determined by light scattering with a particles size analyzer in a $10 \mathrm{~nm}-2 \mathrm{~mm}$ range.

\subsection{Definition of the parameters used for the evaluation of the tests}

The evaluation of the performances of the different tests has been realised by three different parameters taking into account the factors affecting all the bio-technological processes. First, a good fluid-dynamic within the reactor was important to ensure sufficient mass and heat transfer and a good contact between the substrates and the enzymes, avoiding inhibition with too high mechanical shear stress of the impeller. The 
second factor was mixing energy consumption calculated from torque measurement.

Finally, the cellulose conversion was the last factor to evaluate the bioprocess performances. The three parameters used to express these three factors are respectively the mixing time, the energy consumption and the glucose concentration at the beginning and at the end of the enzymatic hydrolysis.

\subsubsection{The Mixing Time}

Mixing time (tm) is the characteristic parameter used to investigate the performance of stirred tank reactors. Mixing time is defined as the period of time necessary to achieve the desired level of homogeneity in a given vessel (Jafari et al., 2005) and it is often used as an indication of impeller effectiveness. The shorter the mixing time the more effective the blending (Gumienna et al., 2011). The mixing time was determined by the pH pulse method (Tan et al., 2011), (Correa et al., 2016). $10 \mathrm{~mL}$ of $\mathrm{NaOH}(2 \mathrm{~N})$ solution will be put in the reaction medium. Mixing time was estimated as the time required for the $\mathrm{pH}$ to reach $95 \%$ of its final value. The determination of the mixing time, has been conducted at the beginning of the tests, when the adjustment of the acid reaction medium is necessary to reach the operative $\mathrm{pH}$ value of 5.5 , required by the enzymatic hydrolysis. Mixing time has been also evaluated at the end of the hydrolysis, before the discharging of the reactor.

\subsubsection{Power input required by the mixing system}

The power consumption was determined by means of a torque meter mounted on the shaft of each impeller. Due to the friction factor, the torque generated by the motor $(\mathrm{Mm})$ is not fully transmitted by the impeller to the reaction medium (Wang et al., 2012). The corrected torque value Mc was calculated by subtracting the residual torque from each measurement: 
189 where $\mathrm{Mm}$ is the measured torque and $\mathrm{Mr}$ is the residual torque, in $\mathrm{Nm}$, respectively.

$190 \mathrm{Mr}$ is determined by measuring the torque at $50 \mathrm{rpm}$. The values of $\mathrm{Mm}$ were recorded 191 each second by the torque-meter for all the duration of the test ( $5 \mathrm{~h})$. An average value 192 of Mc has been calculated each 15 minutes $(\Delta t)$ and used for the following calculation 193 of the power $(\mathrm{P})$ and mixing energy consumptions $(\mathrm{E})$ :

$194 \quad \mathrm{P}(\mathrm{W})=\mathrm{Mc} 2 \pi \mathrm{N}$

195 Where $\mathrm{N}$ is the rotational speed of the helicoidal impeller, fixed to $50 \mathrm{rpm}$ for all the 196 tests. Finally, the mixing energy consumption is given by the equation:

$197 \quad \mathrm{E}(\mathrm{J})=\Sigma \mathrm{P}_{\mathrm{i}} \Delta \mathrm{t}_{\mathrm{i}}$

Where $P_{i}$ is the power consumption for the th-esim time range $\Delta t_{i}$ of 15 minutes (900 s).

\subsubsection{Conversion of ligno-cellulosic materials}

200 In order to evaluate if the best operative conditions, obtained by the tests, are adequate 201 for the degradation activity of the enzymes, the conversion of the ligno-cellulosic compounds into glucose has been also considered. Thus, the glucose concentration in the reaction medium has been also measured at the beginning and at end of the tests.

\subsection{Different viscosity between wheat straw and miscanthus}

$<$ Figure 2 $>$

207

$<$ Figure 3 $>$ 
The tests demonstrated that the enzymatic hydrolysis depends on the substrates used to feed the reactor (Figure 2 and Figure 3): the torque (Mc) was higher for wheat straw than for miscanthus. In addition, the wheat straw has recorded a considerable decreasing of the torque values between the beginning and the end of the tests. On the one hand, the required torque for the reaction medium mixing at $50 \mathrm{rpm}$ dropped from $0.64 \mathrm{Nm}$ to $0.22 \mathrm{Nm}$ for the S-B test and to $0.09 \mathrm{Nm}$ for the S-FB50 and S-FB35 tests (Figure 2).

On the other hand, the torque in the case of miscanthus tests had a lower reduction: it passed from 0.09 to $0.045 \mathrm{Nm}$ (Figure 3). These different values can be explained by the viscosity. The reaction medium composed by $20 \% \mathrm{w} / \mathrm{w}$ DM of wheat straw particles was very viscous, having an apparent viscosity of $200.1 \pm 1.7 \mathrm{cP}$ at $10 \% \mathrm{w} / \mathrm{w} \mathrm{DM}$ and of $420.1 \pm 3.1 \mathrm{cP}$ at $20 \% \mathrm{w} / \mathrm{w} \mathrm{DM}$. The miscanthus presented a gentle fluid-dynamic behavior with low viscosity values of $43.81 \pm 4.49 \mathrm{cP}$ and $79.40 \pm 4.05 \mathrm{cP}$ at respectively $10 \%$ and $20 \% \mathrm{w} / \mathrm{w}$ DM. The torque values for miscanthus were only $5-10$ times higher than torque required by water (about $0.01 \mathrm{Nm}$ ) at $50 \mathrm{rpm}$ (Figure 3). The difference in viscosity had an immediate effect on mixing time (Table 3). Mixing time was higher than $50 \mathrm{~s}$ for the wheat straw and only of $17 \mathrm{~s}$ for the miscanthus. The high values of DM and the complex polymerization of the lignocellulosic substrates allowed to define the reaction medium as pseudoplastic fluids, whose behavior can be described by models such as power law, Bingham, Cason and Herschel-Bulkley models (Sotaniemi et al., 2016). The remarkable difference between wheat straw and miscanthus viscosity could be due to a different physical structure of the two substrates. Table 1 shows that wheat straw had a higher degree of porosity than miscanthus $(73 \%$ and $52 \%$ respectively) and a higher average diameter value of pores (about 43,100 nm and $16,400 \mathrm{~nm}$ respectively). This porosity determined also a different water absorption, 
higher for wheat straw than for miscanthus particles. This theory has been confirmed by the experimental results obtained from the measurement of the beginning time of percolation and the amount of the water adsorption: $25 \mathrm{~s}$ and $45 \mathrm{~mL}$ for the wheat straw and $49 \mathrm{~s}$ and $29 \mathrm{~mL}$ for the miscanthus. The higher water absorption of straw caused a lower amount of liquid in the reaction medium and consequentially an increase of the viscosity. Therefore, there was a reduction of the dispersion and of the homogenization of wheat straw particles within the reactor. Mondebach and Nokes (2013) explained that water reduces the viscosity of the slurry by increasing the lubricity of the particles. It permits to decrease the required shear stress and consequentially the power input for mixing. The water absorption was mainly due to macroporosity which is twice bigger for wheat straw than for miscanthus (Table 1) (Ros et al., 2013). It is also interesting to observe that the total porosity of the substrates was not given by microporosity and mesoporosity (which was almost $0 \mathrm{~mL} / \mathrm{g}$ ). The different porosity degree also permits to explain the apparent density (Table 1), which was about $430 \mathrm{~kg} / \mathrm{m}^{3}$ for wheat straw and $520 \mathrm{~kg} / \mathrm{m}^{3}$ for miscanthus. It was coherent with the density measured at $0.2 \mathrm{MPa}: 0.7$ and $0.93 \mathrm{~g} / \mathrm{mL}$ for wheat straw and miscanthus, respectively.

The analysis for the determination of the average diameter value of the particle, reported in Table 1, permitted to verify that the wheat straw particles are slightly bigger than miscanthus, contributing to the further increasing of the reaction medium's viscosity for the wheat straw.

Finally, the higher viscosity of straw was also due by a different distribution of the three major lignocellulosic components (lignin, hemicellulose and cellulose) (Table 1). In fact, Lewandowska et al., 2016 have reported that miscanthus has a higher content of hemicellulose, the most easily degradable and flexible compounds between ligno- 
cellulosic materials, and a lower concentration of lignin which gives the property of rigidity to ligno-cellulosic polymers (Table 1).

\subsection{Batch and fed-batch tests}

259 The effects of the enzymatic hydrolysis have been summarized in Table 3. All the tests

260 have recorded the reduction of the mixing time. It moved from about $50 \mathrm{~s}$ to $40 \mathrm{~s}$ for the wheat straw, which means a reduction of about $20 \%$. While, the mixing time values declined from $17 \mathrm{~s}$ to $10.5 \mathrm{~s}$ for miscanthus, with a reduction of more than $35 \%$.

$<$ Table 3>

264 The mixing time reduction was clearly imputable to the decreasing of the reaction medium by the effect of the enzymatic hydrolysis. The enzymes attacked the cellulose permitting a significant structural change in terms of the crystallinity and polymerization degrees (Adani et al., 2011). Consequentially, the mixing inside the reactor was improved with a reduction of the torque transmitted by the motor to the 269 impeller.

Figure 3 reports the torque values during time for batch and fed-batch tests with miscanthus substrate. All the tests have followed almost the same decreasing evolution

272 of torque during time, recovering almost the same values, from $0.07 \mathrm{Nm}$ at the beginning of the test (average value for all the miscanthus tests) to $0.045 \mathrm{Nm}$ at the end of the hydrolysis. On the contrary, strong difference in the torque values have been recorded for the wheat straw, where the loading reactor strategy had a great impact $0.65 \mathrm{Nm}$. The tests S-FB65, S-FB50 and S-FB35 had an initial torque more and more inferior $(0.45,0.19$ and $0.12 \mathrm{Nm}$ respectively, Figure 2$)$ due to the minor mass loaded at 
the beginning of the test. During the first additions, the benefic effects of hydrolysis were not enough efficient and the viscosity remained high, so that a considerable increasing of the torque has been recorded. By the time, the action of the enzymes allowed a sufficient denaturation of the ligno-cellulosic materials (Adani et al., 2011) and the new substrates additions have been quickly homogenized in the reaction medium. Figure 2 also shows that the reduction of the torque was more efficient for the S-FB50 and S-FB35, whose final values of the torque were around $0.09 \mathrm{Nm}$, inferior than the final values of torque of about $0.23 \mathrm{Nm}$ for the S-FB65. It suggests that a gradual addition of the substrates had a beneficial effect on the denaturation of the ligno-cellulosic materials, probably due to the high concentration of enzymes (which are fed at the beginning of the test) for mass of substrates initially charged. In general, it has been demonstrated that fed-batch offers advantages in the enzymatic hydrolysis over the batch mode: the initial substrates quantity fed into the reactor is lower, so diffusion and mixing limitations can be minimized. In addition, fed-batch strategy permitted to the enzymes to better liquefy the recalcitrant lignocellulosic materials before additional solids addition (Mondebach and Nokes, 2013).

As reported in the previous part, torque is strictly linked to the power demand of the mixing system and to the energy consumption for the reaction medium agitation. For this reason, the lower torque of S-FB50 and S-FB35 implied also energetic and economic advantages. Table 3 reported the energy consumption during the tests. It was evident that a gradual addition of the feeding permitted a considerable saving of electrical energy: the S-B test required over $32.5 \mathrm{~kJ}$, while S-FB35 test required only 9.5 $\mathrm{kJ}$, which means an energy reduction of about $60 \%$. Also, all the tests having miscanthus as substrate required between 7 and almost $5 \mathrm{~kJ}$, with a slightly energetic 
reduction for M-FB50 and M-FB35 tests which required $4.8 \mathrm{~kJ}$ against the $7 \mathrm{~kJ}$ of the M-B and M-FB65. This little difference for the miscanthus tests can be easily explained by considering the lower viscosity of this substrate for the reasons previously discussed.

Regarding the cellulose conversion into glucose, Table 3 reported glucose concentration in the reaction medium at the beginning and at the end of the tests. There is no difference between the tests conducted with the wheat straw and the miscanthus. About $19.00-19.50 \mathrm{~g} / \mathrm{L}$ of glucose have been found in wheat straw tests after the hydrolysis stage. A slightly higher concentration of $20.00-21.00 \mathrm{~g} / \mathrm{L}$ has been obtained from miscanthus. It is probably due to the different distribution of the three ligno-cellulosic (lignin, cellulose and hemicellulose) between wheat straw and miscanthus, reported in Table 1. Wheat straw had a major concentration of cellulose, which is the main precursor of glucose production. Miscanthus had a minor lignin which limits the access to cellulose to the enzymes, by its more external position between all the lignocellulosic polymers and by its strong covalent bonds (Elgharbawy et al., 2016). The work of Adani et al. (2011) confirmed that the access of cellulase enzymes to crystalline cellulose was greatly reduced by the presence of some compounds, in particular lignin and other structural proteins. Anyway, as previously reported, a short hydrolysis time of $5 \mathrm{~h}$ allowed to achieve only a partial conversion of the substrates, and longer times are necessary to complete the cellulose conversion into glucose. Finally, if the fed-batch permitted to have benefic effects on the mixing and consequentially a strong reduction in the energetic consumption, it was irrelevant for the glucose concentration. This result was coherent with the review work of Modenbach and Nokel (2013) which has concluded their analysis asserting that the fed-batch mode has given unclear results in the cellulose conversion into glucose. 


\subsection{Batch tests with straw-miscanthus mixture}

328 Batch tests (Table 2) have been conducted using a mixture of wheat straw and

329 miscanthus at different concentrations in order to observe when the effect of wheat

330 straw on the viscosity begins to decline. Figure 4 reports the torque values of these

331 batch tests and, for comparisons, the ones of S-B and M-B tests. It has been confirmed

332 that mixing time, torque and energetic consumption of SM-80:20 were still very

333 influenced by the presence of wheat straw, like SB Test. However, when the ratio of

334 miscanthus in the reaction medium reached the $30 \% \mathrm{w} / \mathrm{w}$ (SM-70:30), the viscosity

335 dropped down and its behavior was almost the same of M-B test. It means that the

336 content of water absorbed into the internal porosity of the wheat straw is not sufficient

337 to compromise an adequate lubrication of the particles, allowing a good mixing of the

338 reaction medium.

\section{CONCLUSIONS}

340 The physical properties influence on the reaction medium viscosity at high DM

341 concentration has been studied. Batch test with straw was characterized by bad mixing

342 and high energy consumption. It was due to the high porosity and to high water

343 absorption of straw which caused an increase of the reaction medium viscosity. The

344 problem can be solved or by the fed-batch mode, which permitted to reduce diffusion

345 and mixing limitations, or preparing a mixture of wheat straw-miscanthus with a

346 minimal ratio of miscanthus of $30 \% \mathrm{w} / \mathrm{w}$. By these ways, it was possible to reduce the

347 mixing time and the energy consumption from 30 to $5 \mathrm{~kJ}$.

\section{References}


1. Adani, F., Papa, G., Schievano, A., Cardinale, G., D’Imporzano, G., Tambone, F., 2011. Nanoscale structure of the cell wall protecting cellulose from enzyme attack. Environmental Science \& Technology 45 (3), $1107-$ 1113.

2. APHA/AWWA/WEF., 1998. Standards Methods for the Examination of Water and Wastewater. United Book Press Inc. Baltimore. Maryland.

3. Balat, M., 2011. Production of bioethanol from lignocellulosic materials via the biochemical pathway: A review. Energy conversion and management 52, $858-875$.

4. Battista, F., Fino, D., Mancini, G., 2016b. Optimization of the biogas production from coffee production waste. Bioresource Technology 200, 884890.

5. Battista, F., Fino, D., Mancini, G., Ruggeri, B., 2016c. Mixing in digesters used to treat high viscosity substrates: The case of olive oil production wastes. Journal of Environmental Chemical Engineering 4, 915-923.

6. Battista, F., Mancini, G., Ruggeri, B., Fino, D., 2016a. Selection of the best pretreatment for hydrogen and bioethanol production from olive oil waste products. Renewable Energy 88, 401-407.

7. Boussaid, A., Saddler, J. N., 1999. Adsorption and activity profiles of cellulases during the hydrolysis of two Douglas fir pulps. Enzyme and Microbial Technology 24, $138-143$.

8. Cara, C., Moya, M., Ballesteros, I., Negro, M.J., González, A., Ruiz, E., 2007. Influence of solid loading on enzymatic hydrolysis of steam exploded 
or liquid hot water pretreated olive tree biomass. Process Biochemistry, 42, 1003-1009.

9. Clomburg, J.M., Gonzalez, R., 2013. Anaerobic fermentation of glycerol: a platform for renewable fuels and chemicals. Trends Biotechnol. 31 (1), 2028.

10. Corre, L.J., Colli Badino, A., Gonc, A.J., Cruz, A., 2016. Mixing design for enzymatic hydrolysis of sugarcane bagasse: methodology for selection of impeller configuration. Bioprocess Biosyst. Eng. 39, 285-294.

11. Elgharbawy, A.A., Alam, M.Z., Moniruzzaman, M., Goto, M., 2016. Ionic liquid pretreatment as emerging approaches for enhanced enzymatic hydrolysis of lignocellulosic biomass. Biochemical Engineering Journal 109, $252-267$.

12. Gumienna, M., Lasik, M., Szambelan, K., Czarneck, Z., 2011. Reduction of water consumption in bioethanol production from triticale by recycling the stillage liquid phase. Acta Sci. Pol. Technol. Aliment. 10 (4), 467-474

13. Horvath, G., Kawazoe, K., 1983. Method for calculation of effective pore size distribution in molecular sieve carbon, J. Chem. Eng. Jpn. 16, 470.

14. Jafari, M., Soltan Mohammadzadeh, J.S., 2005. Mixing time, homogenization energy and residence time distribution in a gas-induced contactor. Chemical Engineering Research and Design. 83 (A5), 452-459.

15. Jorgensen, H., Vibe-Pedersen, J., Larsen, J., Felby, C., 2007. Liquefaction of Lignocellulose at High-Solids Concentrations. Biotechnology and Bioengineering. $96(5), 862-870$. 
16. Kristensen, J.B., Felby, C., Jørgensen, H., 2009. Yield-determining factors in high-solids enzymatic hydrolysis of lignocellulose. Biotechnology for Biofuels 2, $11-21$.

17. Larsen, J., Ostergaard Petersen, M., Thirup, L., Wen Li, H., Krogh Iversen, F., 2008. The IBUS process of lignocellulosi bioethanol close to a commercial reality. Chem. Eng. Technol. 31, 765-722.

18. Lewandowska, M., Szymanka, K., Kordala, N., Dabrowska, A., Bednarski, W., Juszczuk, A., 2016. Evaluation of mucor indicus and Saccharomyces cerevisiae capability to ferment hydrolysates of rape straw and Miscanthus giganteus as affected by the pretreatment method. Bioresource Technology $212,262-270$.

19. McIntosh, S., Zhang, Z., Palmer, J., Wong, H., Doherty, W.O.S., Vancov, T., 2016. Pilot-scale cellulosic ethanol production using eucalyptus biomass pretreated by dilute acid and steam explosion. Biofules, bioproducts and biorefining 10 (4), 346-358.

20. Mondebach, A.A., Nokel, S.E., 2013. Enzymatic hydrolysis of biomass at high-solids loadings - A Review. Biomass and Bioenergy 56, 526-544.

21. Ros, A.B., Filho, J.T., Barbosa, G.M.C., 2013. Soil physical properties and growth of sweet potato under different soil managements. Revista Brasileira de Ciencia do Solo 37, 242-250.

22. Sotaniemi, V.H., Taskila, S., Ojamo, H., Tanskanen, J., 2016. Controlled feeding of lignocellulosic substrates enhances the performance of fed-batch enzymatic hydrolysis in a stirred tank. Biomass and Bioenergy 91, 271-277. 
23. Tan, R.K., Eberhard, W., Buchs, J., 2011. Measurement and characterization of mixing time in shake flasks. Chemical Engineering Science 66, 440-447.

24. Wang, X., Fradette, L., Takenaka, K., Tanguy, P., 2012. Effect of Operating Parameters on the Mixing Performance of the Superblend Coaxial Mixer. Industrial \& Engineering Chemistry Research 51, 1826-1833.

25. Xue, Y., Jameel, H., Phillips, R., Chang, H., 2012. Split addition of enzymes in enzymatic hydrolysis at high solids concentration to increase sugar concentration for bioethanol production. Journal of Industrial and Engineering Chemistry 18, 707-714.

26. Zhang, Y., Ghaly, A.E., Li, B., 2012. Physical properties of wheat straw varieties cultivated under different climatic and soil conditions in three continents. American Journal of Engineering and Applied Sciences, 5 (2), 98-106.

27. Zhao, Z., Fred Cannon, S., Nieto-Delgado, C., Pena, L., 2016. Lignin/collagen hybrid biomaterials as binder substitute for specialty graphites and electrodes. Carbon 108, 303-317.

28. Zhou, J., Wang, Y.H., Chu, J., Zhuang, Y.P., Zhang, S.L., Yin, P., 2008. Identification and purification of the main components of cellulases from a mutant strain of Trichoderma viride T 100-14. Bioresour Technol 99, 68266833. 
$440 \quad$ Figures

441 Figure 1. The reactor and the helicoidal impeller used for the enzymatic hydrolysis of 442 wheat straw and miscanthus.

443 Figure 2. Torque values vs time for batch and fed-batch tests having wheat straw as 444 substrate.

445 Figure 3. Torque values vs time for batch and fed-batch tests having miscanthus as 446 substrate.

447 Figure 4. Torque values vs time for batch tests having wheat straw and miscanthus as 448 substrates.

\section{Tables}

450 Table 1. Chemical and physical characteristics of wheat straw and miscanthus.

451 Table 2. Abbreviation and description of the tests.

452 Table 3. Mixing time, energy consumption and glucose concentration of the tests. 
Figure 1

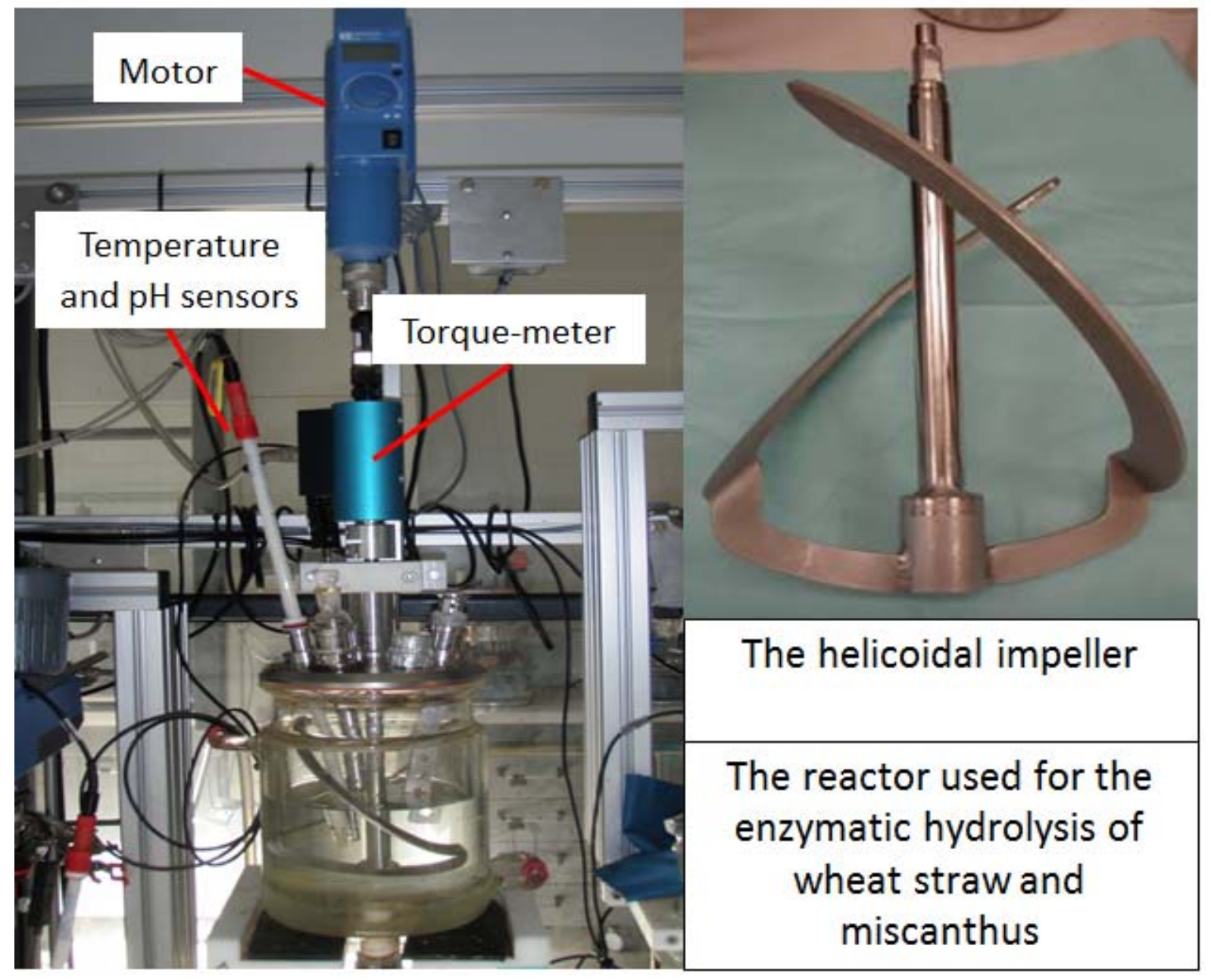


Figure 2

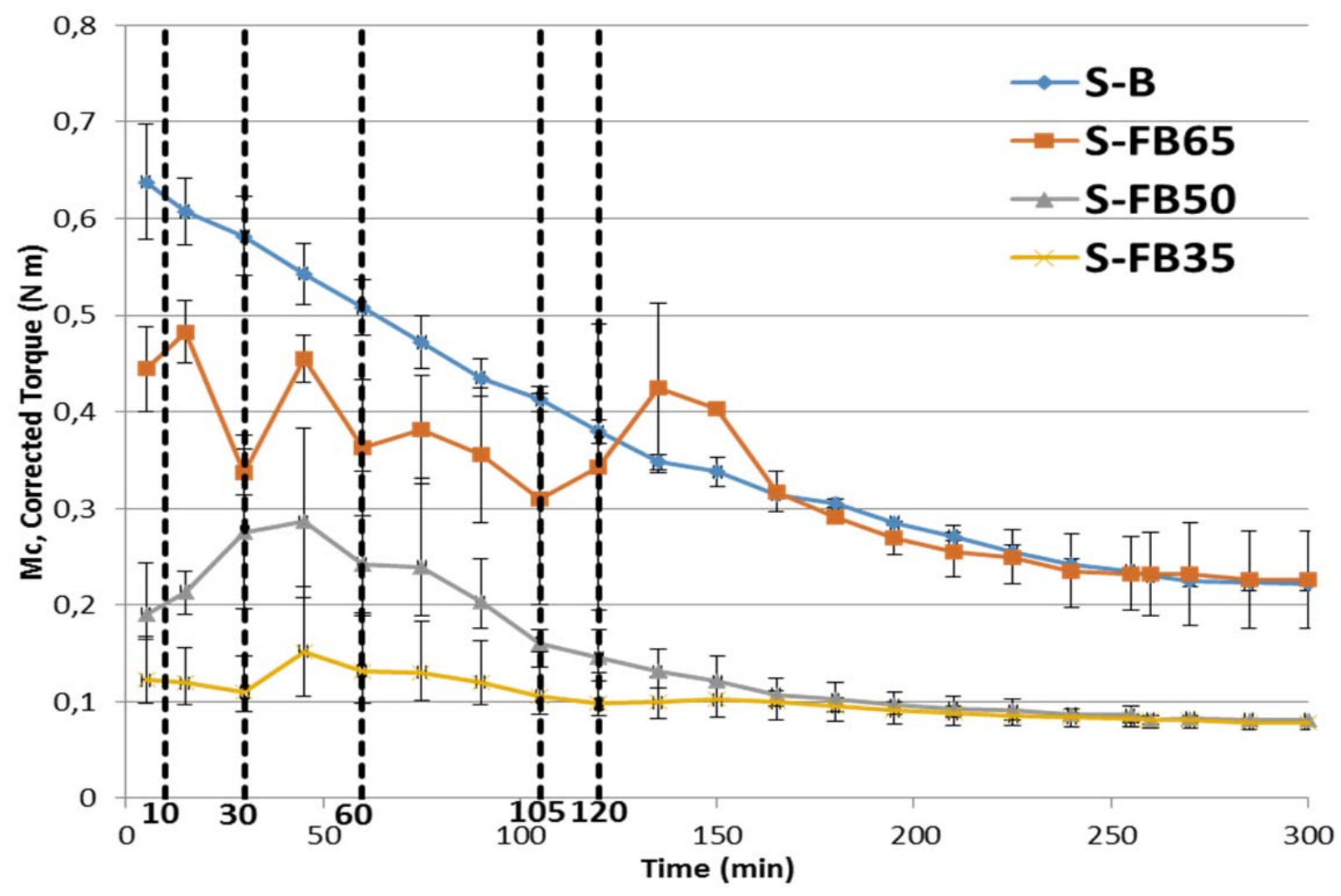


Figure 3

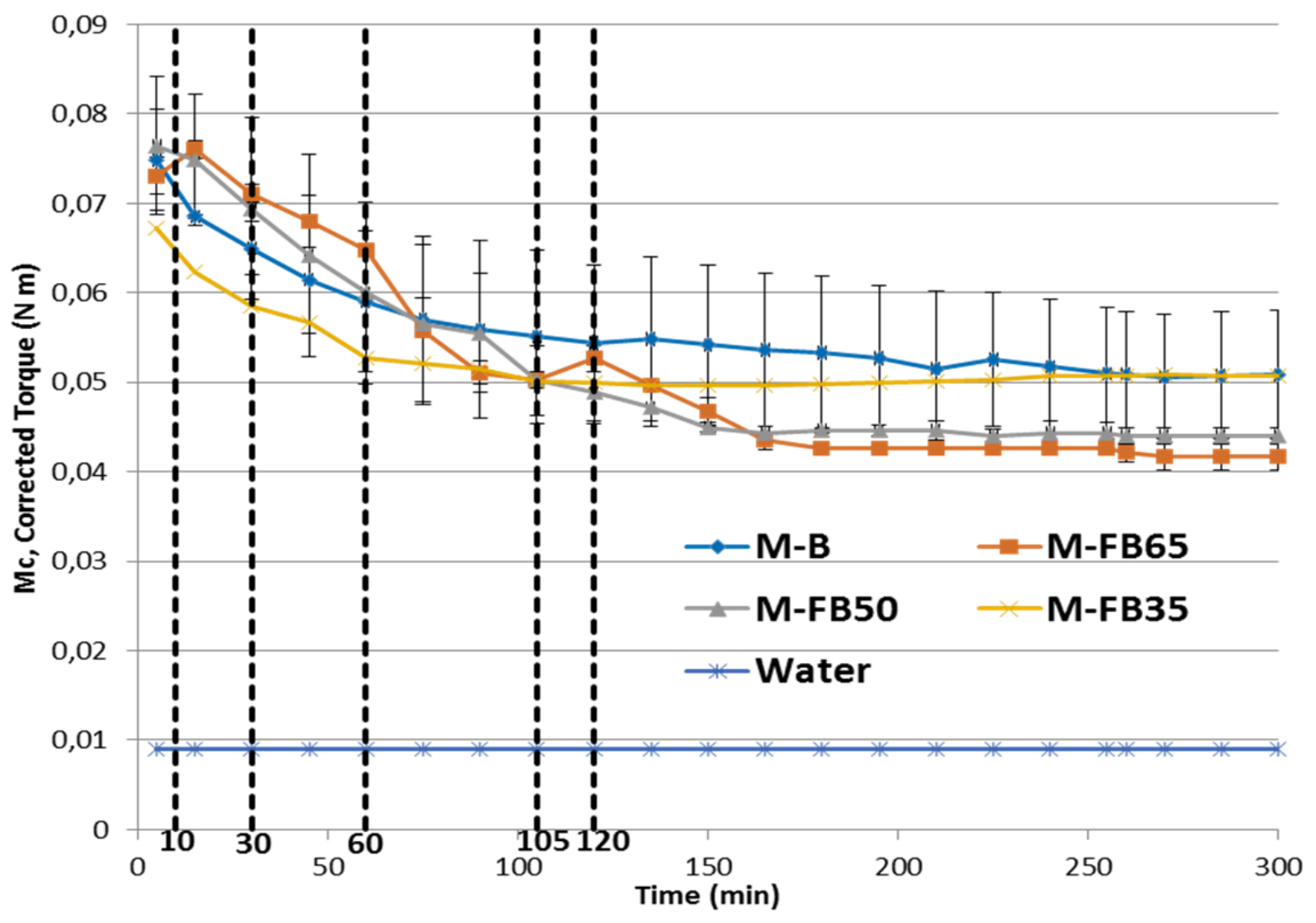


Figure 4

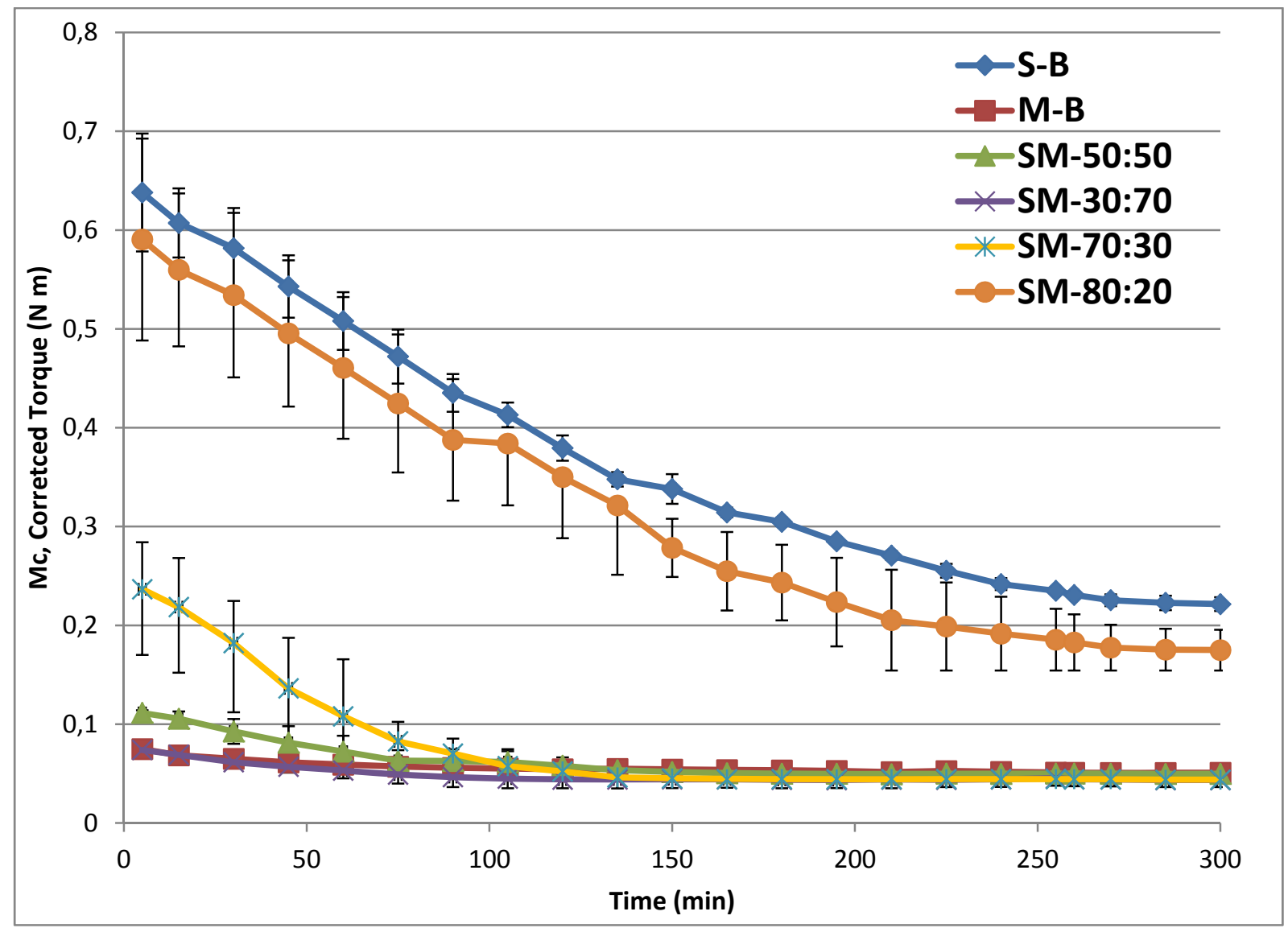


Table 1

\begin{tabular}{|c|c|c|}
\hline & Miscanthus & Wheat Straw \\
\hline $\begin{array}{l}\text { DM content }(\% w / w) \\
\text { Cellulose content }(\% w / w) \\
\text { Hemicellulose content }(\% w / w) \\
\text { Lignin content }(\% w / w)\end{array}$ & $\begin{array}{c}73.35 \pm 1.01 \\
45.30 \pm 2.35 \\
27.10 \pm 1.23 \\
9.80 \pm 0.14\end{array}$ & $\begin{array}{l}70.79 \pm 1.29 \\
49.20 \pm 2.07 \\
12.20 \pm 1.91 \\
14.90 \pm 1.41\end{array}$ \\
\hline $\begin{array}{l}\text { Apparent density }\left(\mathrm{kg} / \mathrm{m}^{3}\right) \\
\text { Density a } 0.212 \mathrm{MPa}(\mathrm{g} / \mathrm{mL})\end{array}$ & $\begin{array}{c}516.10 \pm 8.67 \\
0.93 \pm 0.05\end{array}$ & $\begin{array}{c}433.90 \pm 13.40 \\
0.70 \pm 0.04\end{array}$ \\
\hline $\begin{array}{l}\text { Porosity }(\%) \\
\text { Volume of macroporosity }(\mathrm{mL} / \mathrm{g}) \\
\text { Volume of mesoporosity }(\mathrm{mL} / \mathrm{g}) \\
\text { Volume of microporosity }(\mathrm{mL} / \mathrm{g}) \\
\text { Average diameter of the pores }\left(\mathrm{nm}^{3}\right)\end{array}$ & $\begin{array}{c}52.00 \pm 2.60 \\
0.34 \pm 0.03 \\
0.02 \pm 0.00 \\
0.00 \pm 0.00 \\
16461.10 \pm 823.06\end{array}$ & $\begin{array}{c}73.00 \pm 3.65 \\
0.65 \pm 0.07 \\
0.02 \pm 0.00 \\
0.00 \pm 0.00 \\
43128.40 \pm 2156.42\end{array}$ \\
\hline $\begin{array}{l}\text { d (0.1) } \mu \mathrm{m} \\
\text { d (0.5) } \mu \mathrm{m} \\
\text { d (0.9) } \mu \mathrm{m}\end{array}$ & $\begin{array}{c}158 \\
516 \\
1210\end{array}$ & $\begin{array}{c}175 \\
551 \\
1340\end{array}$ \\
\hline
\end{tabular}


Table 2

\begin{tabular}{|ll|}
\hline Labels & Description of the tests \\
\hline S-B & $\begin{array}{l}\text { Batch test with wheat straw } \\
\text { Fed batch test with } 65 \% \text { of the total mass of wheat straw loaded at the beginning of the } \\
\text { experiment } \\
\text { Fed batch test with } 50 \% \text { of the total mass of wheat straw loaded at the beginning of the } \\
\text { experiment }\end{array}$ \\
S-FB50 & $\begin{array}{l}\text { Fed batch test with } 35 \% \text { of the total mass of wheat straw loaded at the beginning of the } \\
\text { experiment }\end{array}$ \\
\hline M-FB35 & $\begin{array}{l}\text { Batch test with miscanthus } \\
\text { Fed batch test with } 65 \% \text { of the total mass of miscanthus loaded at the beginning of the }\end{array}$ \\
M-FB65 & $\begin{array}{l}\text { experiment } \\
\text { Fed batch test with } 50 \% \text { of the total mass of miscanthus loaded at the beginning of the } \\
\text { experiment }\end{array}$ \\
M-FB35 & $\begin{array}{l}\text { Fed batch test with } 35 \% \text { of the total mass of miscanthus loaded at the beginning of the } \\
\text { experiment }\end{array}$ \\
\hline $\begin{array}{l}\text { SM-80:20 } \\
\text { SM-70:30 }\end{array}$ & $\begin{array}{l}\text { Batch test with a mixture composed by } 80 \% \text { of wheat straw and } 20 \% \text { of miscanthus } \\
\text { Batch test with a mixture composed by } 50 \% \text { of wheat straw and } 50 \% \text { of miscanthus } \\
\text { SM-50:50 }\end{array}$ \\
SM-30:70 & \begin{tabular}{l} 
Batch test with a mixture composed by $30 \%$ of wheat straw and $70 \%$ of miscanthus \\
\hline
\end{tabular}
\end{tabular}


Table 3

\begin{tabular}{|c|c|c|c|}
\hline & $\begin{array}{c}\text { Mixing Time } \\
\text { (s) }\end{array}$ & $\begin{array}{c}\text { Energy Consumption } \\
\text { (J) }\end{array}$ & $\begin{array}{l}\text { Glucose concentration } \\
\text { (g/L) }\end{array}$ \\
\hline $\begin{array}{l}\text { Water } \\
\text { Wheat Straw at } \mathrm{t}=0\end{array}$ & $\begin{array}{c}3.33 \pm 0.44 \\
53.27 \pm 2.10\end{array}$ & $\begin{array}{c}847.12 \pm 9.42 \\
\mathrm{xxxxxxxxxxxx}\end{array}$ & $\begin{array}{c}\mathrm{XXXXXXXXXX} \\
4.11 \pm 0.15\end{array}$ \\
\hline $\begin{array}{l}\text { S-B } \\
\text { S-FB65 } \\
\text { S-FB50 } \\
\text { S-FB35 }\end{array}$ & $\begin{array}{l}41.28 \pm 1.81 \\
42.57 \pm 1.50 \\
41.20 \pm 1.64 \\
39.20 \pm 1.68 \\
\end{array}$ & $\begin{array}{c}32,623.21 \pm 272.94 \\
34,105.87 \pm 797.05 \\
13,028.88 \pm 1010.21 \\
9,567.57 \pm 1442.52\end{array}$ & $\begin{array}{l}18.42 \pm 1.23 \\
19.96 \pm 0.83 \\
19.54 \pm 1.26 \\
19.67 \pm 1.21 \\
\end{array}$ \\
\hline Miscanthus at $\mathrm{t}=0$ & $17.20 \pm 1.26$ & $\operatorname{xxxxxxxxxxx}$ & $3.51 \pm 0.18$ \\
\hline $\begin{array}{l}\text { M-B } \\
\text { M-FB65 } \\
\text { M-FB50 } \\
\text { M-FB35 }\end{array}$ & $\begin{array}{l}11.26 \pm 0.84 \\
10.00 \pm 2.17 \\
10.42 \pm 0.85 \\
10.16 \pm 0.57 \\
\end{array}$ & $\begin{array}{l}6,814.98 \pm 635.90 \\
7,287.02 \pm 150.41 \\
4,788.05 \pm 263.05 \\
4,888.74 \pm 128.19 \\
\end{array}$ & $\begin{array}{l}21.85 \pm 0.25 \\
20.10 \pm 1.15 \\
20.11 \pm 0.74 \\
20.25 \pm 0.85 \\
\end{array}$ \\
\hline $\begin{array}{l}\text { SM-80:20 } \\
\text { SM-70:30 } \\
\text { SM-50:50 } \\
\text { SM-30:70 } \\
\end{array}$ & $\begin{array}{l}38.57 \pm 2.37 \\
36.50 \pm 1.42 \\
24.50 \pm 3.53 \\
15.50 \pm 2.12 \\
\end{array}$ & $\begin{array}{c}30,548 \pm 542.34 \\
7,946.21 \pm 124.91 \\
5,661.82 \pm 476.88 \\
4,492.21 \pm 85.43 \\
\end{array}$ & $\begin{array}{l}20.21 \pm 0.85 \\
19.81 \pm 0.63 \\
20.87 \pm 1.35 \\
20.57 \pm 1.01 \\
\end{array}$ \\
\hline
\end{tabular}

